\title{
The cost of risk management and multifunctionality in forestry: a simulation approach for a case study area in Southeast Germany
}

\author{
Stefan Friedrich ${ }^{1}(0)$ Torben Hilmers $^{2} \cdot$ Claudia Chreptun $^{1} \cdot$ Elizabeth Gosling $^{1} \cdot$ Isabelle Jarisch ${ }^{1} \cdot$ Hans Pretzsch $^{2}$. \\ Thomas Knoke ${ }^{1}$
}

Received: 21 August 2020 / Revised: 19 February 2021 / Accepted: 27 May 2021 / Published online: 6 June 2021

(c) The Author(s) 2021

\begin{abstract}
Forest management faces growing uncertainty concerning environmental conditions and demand for ecosystem services. To help forest managers consider uncertainty, we applied a robust and multi-criteria approach to select the optimal composition of a forest enterprise from 12 stand types. In our simulation, the forest enterprise strives for either financial return or a multi-criteria forest management considering financial return, carbon storage and forest ecosystem stability. To quantify the influence of climate change on these decision criteria, we used the concept of analogous climate zones. Our results provide recommendations for long-term strategies for tree species selection in a Southeast German forest enterprise. The results show that considering both uncertainty and multifunctionality in forest management led to more diversified forest compositions. However, robust and multi-criteria optimisation required the forest enterprise to pay a premium in terms of lower income. Financial returns decreased when forest composition accounted for uncertainty or multiple objectives. We also found that adaptation measures could only partly financially compensate the effects of climate change. As the study is limited to two tree species, including additional tree species, variants of mixing proportions and further silvicultural strategies in the optimisation appears a promising avenue for future research.
\end{abstract}

Keywords Climate change $\cdot$ Tree species selection $\cdot$ Risk management $\cdot$ Robust optimisation $\cdot$ Compromise programming

\section{Introduction}

Climate change drives the frequency and extent of damages to forests (Lindner et al. 2010; Kovats et al. 2014; Allen et al. 2015). Forest owners increasingly experience the natural and financial risks associated with changing climatic conditions. Extreme dry weather conditions in 2018 (Buras et al. 2019; Schuldt et al. 2020), 2019 (Magnusson 2019) and 2020 (Zimmermann and Raspe 2020, 2021) led to massive diebacks and bark beetle infestations

Communicated by Arne Nothdurft.

Stefan Friedrich

st.friedrich@tum.de

1 Institute of Forest Management, TUM School of Life Sciences Weihenstephan, Technical University of Munich, Freising, Germany

2 Chair of Forest Growth and Yield Science, TUM School of Life Sciences Weihenstephan, Technical University of Munich, Freising, Germany in European coniferous stands, with hundreds of thousands of hectares affected (Bundesministerium für Ernährung und Landwirtschaft (BMEL) 2019; Czech Statistical Office 2019; Office National de Forêts 2019). The reforestation of these devastated areas is an urgent topic. Tree species composition and management of these areas determine the resistance against natural hazards and the future provisioning of ecosystem services (Duncker et al. 2012; Gamfeldt et al. 2013; Jactel et al. 2017). Natural adaptation of forest stands to climate change is highly uncertain, as is the extent to which silvicultural measures can buffer negative consequences of climate change for ecosystem service provisioning. Nevertheless, forest owners must select tree species when re-establishing harvested or damaged stands. Additionally, they must decide on silvicultural alternatives and treatment when managing existing forest stands. Therefore, forest owners aim to actively adapt forest management practices and seek silvicultural options under climate change. Decision makers may consider both risk management and the uncertain demand for forest ecosystem services when determining best forest management 
practices. However, balancing risk and return comes at a cost for investors (Markowitz 1952). Previous studies also indicate that multifunctionality, which is considered a key concept to sustainable forest management (Mendoza and Prabhu 2000), may lead to additional costs or lower levels of ecosystem services (Vincent and Binkley 1993; Jacobsen et al. 2013). A quantification of forest management costs that strives for both risk balance and multiple ecosystem services may therefore prove beneficial for choosing the right climate change adaptation strategy for forests.

The extent of rising temperatures and frequency of hazards caused by climate change is uncertain. Climate variation is one of the most important drivers of tree mortality, influencing ecosystem services at a large scale (Neumann et al. 2017). Therefore, forest enterprises will have to manage forest areas with considerably higher natural risks. Increasing temperatures combined with shifts in the distribution of precipitation result in a growing gap between the climatic conditions of the current distribution of many tree species and their ecological niche. As a result, the tree species' productivity and their area of potential distribution may decrease (Davis and Shaw 2001; Falk and Hempelmann 2013; Hanewinkel et al. 2013; Allen et al. 2015; Gutsch et al. 2016). Despite the limited resistance of today's widely distributed coniferous tree species to the effects of climate change (Sykes and Prentice 1996; Thuiller et al. 2005), they still comprise considerable areas of natural or artificial regeneration. For example, the National Forest Inventory in Germany (Thünen Institut 2014) and the Forest Carbon Inventory (Thünen Institut 2019) showed that Norway spruce (Picea abies (L.) H. Karst.) and Scots pine (Pinus silvestris L.) comprised $36 \%$ of all stands younger than 21 years.

In addition to climate change, forest ecosystem management has to consider the preferences of forest owners and the expectations of society. Pasalodos-Tato et al. (2013) described those preferences as a prominent source of uncertainty in forestry. The demand for ecosystem services of future generations may differ from those of today's society, but this has seldom been addressed in forest management (Yousefpour et al. 2012). Hurmekoski and Hetemäki (2013), among others, state that energy from forest products or biochemistry are emerging markets. Additionally, Seidl et al. (2019) emphasised the importance of regulating ecosystem services, for example climate change mitigation (Popkin 2019). Therefore, tree species selection should provide a minimum level for a wide range of ecosystem services regardless of their value for today's forest owners or society (e.g. a possible preference of carbon storage or biodiversity over other regulating or financial ecosystem services). This is especially necessary, as changes to forest composition during a rotation period are difficult to achieve without losses of ecosystem services (Möhring and Rüping 2008).
Forest management may consider these changing natural conditions and changing preferences as uncertainties. Walker et al. (2013) defined five different levels of uncertainty ranging from "complete certainty" to "total ignorance". Within level 1 uncertainty, decision makers know the possible outcomes or scenarios and have point estimates for the probability of each outcome/scenario occurring. Level 2 uncertainty reduces the point estimates to a confidence interval for the probability of each outcome. Level 3 uncertainty still allows decision makers to identify different outcomes and rank them in terms of likelihood. Level 4 uncertainty means that decision makers can still identify alternative scenarios but cannot attribute probabilities or rankings to the likelihood of their occurrence. Level 5 uncertainty means that the future is completely unknown, and decision makers are aware of that fact (Walker et al. 2013). Radke et al. (2017) considered level 4 uncertainty as plausible for the context of climate change. A method to address uncertainty is robust optimisation, which searches for acceptable solutions for a large range of possible input data (Ben-Tal et al. 2009). Some examples of robust decision making in forestry include harvest scheduling (Palma and Nelson 2009), rehabilitation of bark beetle infested forest stands in British Columbia (McDaniels et al. 2012) and optimising stand structure (Messerer et al. 2017). These studies focused on balancing uncertainty associated with a single (usually financial) objective. However, today sustainable forest management may often consider more than one criterion (Biber et al. 2015; Diaz-Balteiro et al. 2017b; Hilmers et al. 2020).

Multi-criteria decision making techniques aim to satisfy different, potentially conflicting demands of decision makers (Shavazipour and Stewart 2019). Multi-objective optimisation has already been applied in forest management to consider several ecosystem services (Diaz-Balteiro et al. 2017a). These previous studies, however, did not consider uncertainty associated with input coefficients. In addition, examples for continuous optimisation are scarce, as many multi-criteria and forest-related studies use discrete, predefined scenarios and apply ex post multi-criteria assessment. Creutzburg et al. (2017) evaluated three different management scenarios in terms of carbon storage, financial return and mature forest habitat under different models for future climate projections. Eggers et al. (2019) and Hilmers et al. (2020) included additional ecosystem services and management scenarios, but still reverted to ex post analyses. As one of the first, Uhde et al. (2017) combined multi-criteria decision making and robust optimisation in forestry to include uncertainty. They used compromise programming to calculate forest portfolios in Chile consisting of different stand types. These portfolios balanced the provisioning of multiple ecosystem services simultaneously. However, indicator values of the ecosystem services provided by each stand type were subject to uncertainty. To account for this, 
Fig. 1 Illustration of the simulation modelling concept

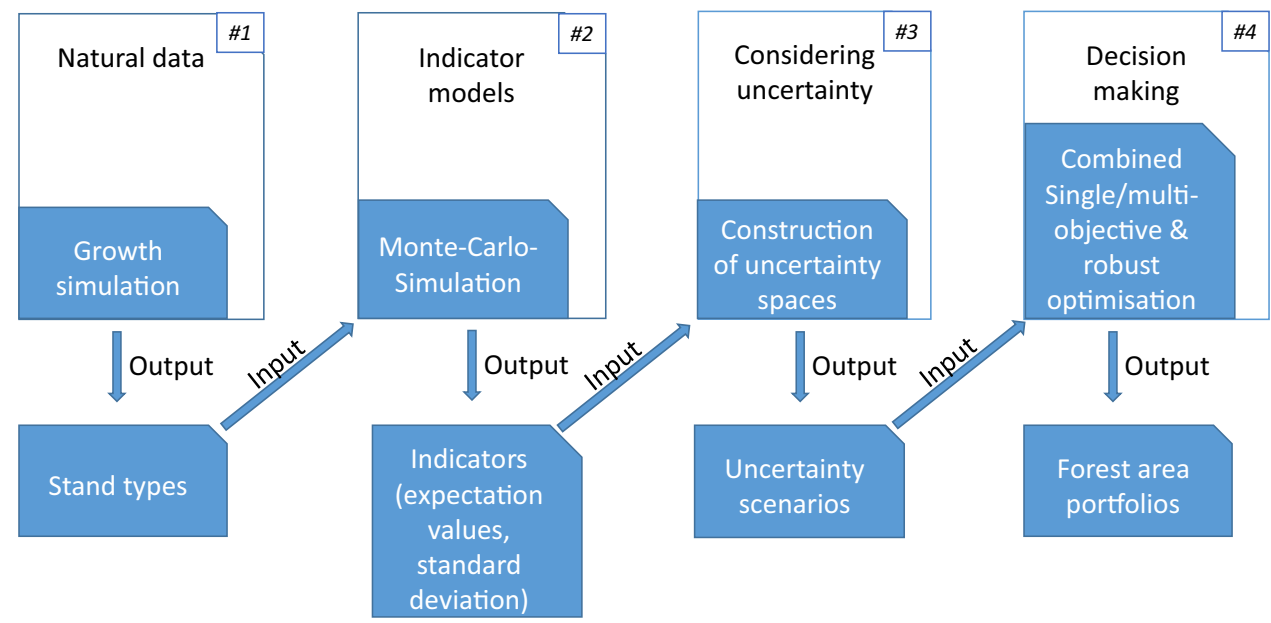

Uhde et al. (2017) integrated non-stochastic robust decision making. Knoke et al. (2020) built upon this approach by optimising land-use in Ecuador with multiple objectives when considering uncertain indicator values. With a reference point method that integrates robust optimisation, they analysed the influence of the decision makers' perspective on future landscape composition. However, none of these case studies addressed site variation and climate change, but focused on specific site conditions under today's climatic conditions.

We address this research gap by formulating a model that integrates robust optimisation to multi-criteria decision making for different regions under climate change. The optimisation algorithm could choose between different management alternatives for stands, not only pure stands of different tree species as in previous studies. Our aim was to support forest enterprises in selecting silvicultural strategies and the optimal composition for their future forest. We want to support multi-criteria tree species and stand type selection as well as minimise trade-offs across multiple uncertainty scenarios and ecosystem service indicators under climate change. Our climatic setting includes both a region considered very suitable for the cultivation of Norway spruce and the analogous climate region for the IPCC's representative concentration pathway (RCP) 8.5 scenario (Pachauri et al. 2015). The influence of the climate on the survival probability of our tree species is the main aspect of climate change considered. Stand types include two of the most common and important tree species in Germany, Norway spruce and European beech, while thinning or not and the length of the rotation period formed the silvicultural setting. Considering uncertainty, climate change and multiple objectives, the following research questions guide our study:

1. Uncertainty: How does considering uncertainty influence optimal forest area composition? How does adaptation to uncertainty influence financial return?
2. Climate change: How does climate change influence optimal forest composition? What are financial consequences if forest owners decide not to adapt to climate change?

3. Multiple objectives: What is the effect of changing from a single objective optimisation to multi-objective optimisation on forest area composition? What are the consequences of changing objectives on ecosystem service provisioning?

\section{Materials and methods}

In this section, we first outline our general modelling approach, before describing the single elements of the model. We designed a static simulation study for Southeast Germany to integrate uncertainty into forest management for tree species and stand type selection. We chose an approach without a dynamic realisation of climate change and adaptation measures, because tree species and especially stand type selection is a long-term investment that cannot easily be adapted. The first component of our model is a simulation of different virtual stand types for management options. They provided the natural data, which we created with the forest growth simulator SILVA 2.3 (Pretzsch et al. 2002) (\#1 in Fig. 1). Tree species and their mixture, treatment and rotation length defined those stand types, thus offering a choice of common silvicultural adaptation measures to climate change. We simulated forest stands for two model regions with substantially different climate parameters. For the stand types, we calculated indicator values with a Monte Carlo simulation (\#2), which included a climate sensitive survival model. Prerequisites for robust decision making under uncertainty were uncertainty scenarios for the indicator values (\#3). These scenarios represent assumptions about a wide range of possible model parameters. Finally, 
Table 1 Labels of the scenarios for the virtual forest enterprise

\begin{tabular}{lll}
\hline Climate scenario & Objective scenario & \\
\cline { 2 - 3 } & Financial return & Multifunctional forests \\
\hline Cool average precipitation & FinCool & MultCool \\
Warm low precipitation (climate change) & FinWarm & MultWarm \\
\hline
\end{tabular}

our simulation optimised the allocation of forest area to different stand types (\#4) to achieve a single or three objectives.

From the results of our optimisation model, we constructed various possible long-term planning compositions for forest enterprises in Southeast Germany facing several scenarios. For a traditional objective, the enterprise strived for financial return only, which was the first baseline. As the second baseline, the enterprise was located in a climate that, at least in the past, has been suitable for the cultivation of Norway spruce and European beech (see below at section "representative stand types"). However, to account for climate change, we assumed an unfavourable climate with a distinct temperature increase and slightly lower precipitation, representing the RCP 8.5 scenario. Furthermore, the forest enterprise managers might choose to include more ecosystem service objectives and strive for multifunctional forestry. This was a scenario for the two respective climate settings. Altogether, this resulted in four scenarios for our virtual forest enterprise (Table 1), which we abbreviated with FinCool, FinWarm, MultCool and MultWarm. The Shannon index served as a measure for diversification of the enterprise land-use portfolios (Nagendra 2002). Usually a measure for biodiversity, Knoke et al. (2015) and Ochoa et al. (2019) used the Shannon index $(\mathrm{H})$ to measure the diversity of an agricultural landscape. But Shannon's H also served as a measure for diversification in economic studies (Adeola and Evans 2017, Pede 2013). We transferred the Shannon index to our study and compared the intensity of diversification in forest portfolios (forest area composition). Shannon's H was calculated from the decimal shares of the forest enterprise area which the stand types had. In this manuscript, the Shannon index compared the diversification of the forest enterprise portfolios. The higher the Shannon index value, the greater the number of stand types included in a given portfolio and the more even their distribution.

\section{Including risk and uncertainty in forest planning with robust optimisation}

We applied a robust and multi-objective methodology to deal with the Level 4 uncertainty associated with climate change (Detten and Hanewinkel 2017) and the uncertain future preferences for various ecosystem services. In robust optimisation, solutions are feasible for many scenarios of input parameter manifestations (Ben-Tal and Nemirovski
1999). An input parameter quantifies the contribution of a specific forest stand type to a specific decision criterion. In our case, we selected ecosystem services (see below "indicator values") to quantify a stand type's contribution to the decision criteria. The indicator values of these ecosystem services serve as parameters. The many combinations of these input parameters are the discrete uncertainty scenarios (Gorissen et al. 2015), which form the surface of the uncertainty spaces. We constructed those with all possible combinations of optimistic values $(E)$ and pessimistic values of ecosystem service indicators for each stand type (see Supplementary S1.1). The uncertainty factor, $m$, regulated the level of uncertainty. $m$ was a multiple of the standard deviation of the indicator value. To calculate the pessimistic values and thus control the size of the uncertainty spaces, we subtracted the standard deviation $m$-times from the optimistic indicator values. Thus, we constructed box-shaped uncertainty spaces and applied a very strict non-stochastic robustness model. We only used indicators where higher indicator levels were considered better. Thus, the standard deviation had to be subtracted to create pessimistic values. For each uncertainty scenario, the best value of $E$ was the ideal point for the respective indicator, which a decision maker tries to achieve. Consequently, we called the most pessimistic value in each uncertainty scenario the anti-ideal point. We analysed the effect of different sizes of the uncertainty spaces with $m \in(1,2,3,4) . m=1$ reflects a forest manager with low risk aversion. We refrained from using $m=0$ or $m=0.5$ as we considered this as risk neutral. $m=3$ is a reasonable level for a forest manager to consider uncertainty in management planning. It spans uncertainty spaces by three times the standard deviation of the indicator estimates, including $99 \%$ of the probability distribution of results. Therefore, we refrained from explaining results for an uncertainty factor of $m=4$, which we considered of low practical relevance. However, optimising with $m=4$ allowed us to check our model for consistent results at larger uncertainty spaces. This span is analogous, for example, to the concept of Value-at-Risk (Jorion 1997, 2009). Here, applications with high standards concerning safety (e.g. medical production) use a $99 \%$-Value-at-Risk, setting a safety threshold that accepts only the worst $1 \%$ of cases. To focus on risk aversion, we limited this concept to the negative side of the results, ignoring positive deviations (opportunities). Thus, the consideration of uncertainty was one-sided and 
Table 2 Objectives and their indicators for the optimisation of forest enterprise area

\begin{tabular}{|c|c|c|c|c|}
\hline Objective & Indicator & Unit & Description & Source \\
\hline Financial services & Financial return (Annuity) & $\begin{array}{l}\text { Euros per hec- } \\
\text { tare and year } \\
\left(\text { Euros ha }{ }^{-1} \mathrm{yr}^{-1}\right)\end{array}$ & $\begin{array}{l}\text { Annualised discounted cash flows } \\
\text { for an unlimited number of } \\
\text { rotations (soil rent) }\end{array}$ & $\begin{array}{l}\text { Blanco et al. (2015), Ficko et al. } \\
\text { (2019) }\end{array}$ \\
\hline Climate protection & Carbon storage & $\begin{array}{l}\text { Tonnes of carbon per } \\
\text { hectare and year } \\
\left(\mathrm{tC} \mathrm{ha}^{-1} \mathrm{yr}^{-1}\right)\end{array}$ & $\begin{array}{l}\text { Contribution of forestry to } \\
\text { climate change mitigation by } \\
\text { storing carbon in living and } \\
\text { dead above ground biomass } \\
\text { and forest products, and carbon } \\
\text { emissions avoided by substitu- } \\
\text { tion }\end{array}$ & $\begin{array}{l}\text { Hernandez et al. (2014), Härtl } \\
\text { et al. (2017), Köhl et al. (2020) }\end{array}$ \\
\hline Ecosystem stability & Survival rate $S$ & Probability $(0<S<1)$ & $\begin{array}{l}\text { A stand's probability of reaching } \\
\text { the rotation age as a proxy } \\
\text { for the stability of the forest } \\
\text { ecosystem }\end{array}$ & $\begin{array}{l}\text { Tom et al. (2007), Araújo et al. } \\
\text { (2011), Lemes et al. (2014), } \\
\text { Keenan (2015), Andersson } \\
\text { et al. (2018) }\end{array}$ \\
\hline
\end{tabular}

again very strict in its robustness. The indicator values of the uncertainty scenarios were the input parameters for the ensuing optimisation process.

\section{Multi-objective optimisation}

Our approach to integrate robust optimisation into multiobjective optimisation was based on Knoke et al. (2020), an agricultural land-use study in Ecuador researching the effect of robust multi-objective optimisation on deforestation. We applied their methodology to a forestry setting and added a worst-case climate change scenario and a sophisticated survival model. Specifically, we used a reference point method (see Estrella et al. (2014) for a description of such methods). The reference point is the relative ideal indicator level that cannot be achieved for all ecosystem services, and uncertainty sets simultaneously, unless a perfect solution exists for only one forest stand type, under all uncertainty scenarios. This was not the case in our study. We aimed to find a solution (i.e. dispersal of stand types) that constituted a compromise between achieved indicator values and the ideal points for each decision criterion across all uncertainty scenarios. The algorithm's objective function, therefore, minimised the maximum distance $\beta$ between the actual performance level of a portfolio and its reference point (Diaz-Balteiro et al. 2007; Estrella et al. 2014; Diaz-Balteiro et al. 2018). As the uncertainty scenarios provided the reference points and indicator values for this compromise solution, we integrated robust optimisation into our multi-criteria approach. To also account for the uncertainty of future preferences for ecosystem services, we refrained from assigning weights to the objectives. This way all objectives had an equal probability to be part of the decision makers' preferences. For a detailed description of the optimisation algorithm and the robustness of the approach, see Knoke et al. (2020) and the supplementary material.

\section{Indicator values}

The input parameters for the optimisation process were indicator values and the associated variation for three ecosystem services: financial services, climate protection and ecosystem stability (see Table 2). As a baseline scenario, we considered the single objective of maximising financial services for a forest enterprise. We chose the financial return in terms of financial annuity as the indicator for financial services from forestry. To account for the uncertainty in the future preferences, however, we created a second scenario, in which we expanded the set of objective functions by two further objectives: climate protection and ecosystem stability. We included carbon storage as an indicator for climate protection in our model. The survival of forest stands against hazards reflected forest stability, allowing for a continuous forest management.

\section{Calculation of the indicators}

This section starts with a description of the general approach to calculate the indicators. The details for the indicators and the specific setting of our model follow in the next subsections and sections. To generate frequency distributions of financial return and carbon storage, we used a Monte Carlo simulation (MCS). From the frequency distributions, we derived the average indicator values and standard deviation of the decision criteria for the reference point method and the uncertainty spaces. Engelhard and Anderson (1983) introduced MCS as a tool to calculate probability distributions of returns. Since then, MCS have successfully supported economic studies under consideration of risk in forestry (Dieter 2001; Thiele et al. 2017). The MCS in our model repeatedly simulated rotation periods where survival probabilities and price fluctuations (Roessiger et al. 2013) served as components of uncertainty. Table A1 in the 
appendix displays all indicator values for the 12 stand types. We calculated the indicators for financial services and climate protection as average values per hectare and year. In the case of financial return, the annuity accounted for an infinite number of rotation periods. We interpreted the values for carbon storage similarly for an unlimited planning horizon, although we only considered a single rotation period. Ecosystem stability in the meaning of a probability was constant for each of the unlimited rotation periods. This allowed for a comparison of stand types and enterprise portfolios with different rotation ages. The starting points for our planning were derived from the climate data present in the WorldClim database (Fick and Hijmans 2017; WorldClim 2018). Past climate data were available for the period 1970 to 2000. The Max-Planck-Institute Earth System Model (MPI-ESM-LR) projected the changes in climate as averages for the years 2060 to 2080 . Accordingly, we set the year 2070 as the representative year for climate change in our study. Our planning horizon is theoretically an unlimited number of rotation periods with constant climatic conditions (Faustmann approach). The different rotation ages, species, mixtures and treatment concepts mentioned here are explained in the section "representative stand types".

\section{Financial return}

The net present value is a common indicator for comparing different investment alternatives (Bullard and Straka 2011). As we intended to vary the rotation age of our stand types, the soil expectation value, SEV (Faustmann 1849), allowed for a better comparison of investment alternatives with different rotation ages. The forest enterprise in our study aimed to maximise the annualised SEV and for the calculation of the annuities, we followed Friedrich et al. (2019). For the simulation, we referred to wood prices achieved by the state forest in Bavaria which are slightly above the Central European level (Bayerische Staatsforstverwaltung/ Bayerische Staatsforsten 1976-2015). The harvesting and extraction costs were subtracted according to Messerer et al. (2017). We applied a discount rate of $2 \%$ as a baseline (Möhring and Rüping 2008). In case a hazard occurred in the MCS, the returns from salvage logging were 50\% lower than during regular harvests. This accounted for reduced timber quality and higher harvesting costs (Dieter 2001).

\section{Carbon storage}

Our model for carbon sequestration follows suggestions by Härtl et al. (2017) who consider the carbon stored in the living biomass and wood products. They also include the substitution of fossil resources for products and energy as a further carbon sink. We extend this approach by including the carbon contained in dead wood. Rock et al. (2008) presented decomposition rates which we applied in our model to reduce the amount of carbon in dead wood over time.

\section{Forest ecosystem stability against hazards}

We defined forest ecosystem stability as the probability $S$ of a forest stand to reach the desired rotation age. We adapted current survival functions for forest stands to the specific stand types and climatic conditions of our study. The model for tree species survival was age dependent and included climatic variables and the share of tree species as covariates (Paul et al. 2019; Brandl et al. 2020). From the survival functions, we calculated survival probability and specific hazard rate as uncertainty components for the MCS. The indicator value for ecosystem stability was the survival probability to reach the planned rotation length. The standard deviation of the binomial distribution of this survival probability was the measure for uncertainty.

\section{Financial consequences of considering uncertainty, multiple objectives and adaptation}

A risk premium is the minimum compensation a riskaverse person would require to accept a risky decision. In our case, this can be a cost accepted by forest managers, when the expected return of a forest portfolio becomes lower as a result of diversification to protect against risks (Klemperer 1996). In the narrow sense of the word, the premium refers to financial returns but we applied the concept to all ecosystem services. To calculate the risk premium, we compared the portfolios' ecosystem service values for different sizes of uncertainty spaces. Analogous to the risk premium, a forest enterprise might have to accept losses under multifunctionality. We defined the "multifunctionality premium" as a cost from shifting from a single objective to multiple objectives, when this leads to lower expected levels for single ecosystem services due to a compromise solution. This multifunctionality premium therefore represents the opportunity costs arising from the waiver of higher ecosystem service provisioning for the single objective. To quantify the financial effect of adaptation measures, we recalculated ecosystem service provisioning for today's optimal composition of stand types with the input coefficients from the climate change scenario. This represented a decision maker who chose not to adapt forests to climate change. We then compared the financial returns of today's portfolio under climate change conditions without adaptation with those of a future optimal forest portfolio. 


\section{Geographical setting and climate scenarios}

To explore the influence of climate change on tree species and stand type selection, we applied the concept of climate analogues (Hallegatte et al. 2007). Climate change will lead to substantially higher temperatures in Germany. For the RCP 8.5 scenario, DWD (2020) projects a short-term temperature increase of 1.1 to $1.5{ }^{\circ} \mathrm{C}$ and long-term increase of $3.8^{\circ} \mathrm{C}$. However, trends in precipitation for Germany are uncertain, although it is likely that precipitation will decrease in summer and increase in winter (Kovats et al. 2014). DWD (2020) concludes from climate simulations that under an RCP 8.5 scenario summer precipitation will decrease by $10 \%$ for the period 2071 to 2100 . We selected two growth districts ${ }^{1}$ from southeast Germany, which fit the climate change projections. Historical climate data for the years 1965 to 1990 (Giorgetta et al. 2013; Fick and Hijmans 2017) showed that the Northeast High Plain had a mean annual temperature of $6.7^{\circ} \mathrm{C}$ and a precipitation of $745 \mathrm{~mm}$ annually and $197 \mathrm{~mm}$ in the warmest quarter. In the Lower Main Area, mean annual temperature was $49 \%$ higher $\left(10^{\circ} \mathrm{C}\right)$, and precipitation in the warmest quarter was $10 \%$ lower $(640 \mathrm{~mm}$ annually and $173 \mathrm{~mm}$ in the warmest quarter). Thus, the Lower Main Area could represent the climate change scenario in the period 2060 to 2080 for the Northeast High Plain as an analogous climate region. Our model assumes a steady climatic state instead of simulating a transition process of climate change. Decisions in forest management mostly have long-term character. For example, forest enterprises cannot reverse tree species selection without the loss of ecosystem services and financial losses (Möhring and Rüping 2008). Therefore, we decided to neglect the transition process and directly started at the worse and more uncertain end of climate change. This is in line with our robust approach to account for the corner points of our box-shaped uncertainty spaces. The transition process induced by climate change with gradually worse growing conditions for tree growth in Germany lies within our uncertainty spaces.

\section{Representative stand types}

Virtual forest stands were used to create stand types for the optimisation algorithm. All simulations for stand development and timber production were carried out with the single-tree, distance-dependent forest growth simulator, SILVA 2.3 (Pretzsch 2002). The simulated stands each covered one hectare. We adjusted SILVA 2.3 for the two different climate

\footnotetext{
${ }^{1}$ Germany is subdivided in growth regions and growth districts as smaller units to account for geological and climatic differences between regions.
}

environments and assumed steady climatic and site conditions (Hanewinkel and Pretzsch 2000). We added biotic and abiotic disturbances to the model with the above mentioned Monte Carlo simulation. Applying the approach given in Friedrich et al. (2019), age dependent survival functions (Paul et al. 2019; Brandl et al. 2020) reduced the probability that the stand types would reach their respective rotation age. These survival functions were climate sensitive, meaning that in the RCP 8.5 scenario the survival of stands was considerably lower. The functions also differentiated between the tree species and were sensitive to admixing of other species. Therefore, European beech had a higher survival rate than Norway spruce, and mixed forest stands were more stable than monocultures. For example, the stand type "Pure Norway spruce-thinned-long (120 years) rotation age" in our analysis had a probability of only $21 \%$ ( -21 percentage points lower compared to the cooler region) to reach the desired rotation age assuming the RCP 8.5 climate scenario (see Table A1). For the same stand type with a share of 50\% of both species, the probability was $57 \%$ and only 14 percentage points lower than in the cooler model region.

The tree species included in our model were European beech and Norway spruce. We justified the tree species selection for our study both from a climatic and managerial point of view. We compared the climatic conditions in the model regions with tree species distribution models. Ammer et al. (2008) showed the climatic envelope of Norway spruce and European beech derived following the method of Huntley et al. (1995). A comparison with our climatic setting shows that the Northeast High Plain lies centrally in the climatic envelope of Norway spruce and slightly closer to the colder frontier of European beech. We consider this a suitable area for the cultivation of both species. The temperature in the region Lower Main Area lies beyond the climatic envelope of Norway spruce. For European beech, the climatic variables are still within the climatic envelope, but clearly shift towards the warmer and drier frontier. Our approach with the climate analogous regions reflects the climate change-induced shift of species distribution that forest managers face today.

From a managerial point of view, Norway spruce and European beech are currently the most frequent and economically important conifer and broadleaved tree species, respectively, and cover large areas of forest in Germany, especially in Southeast Germany. They will continue to cover substantial forest area in the near future: Norway spruce comprised $28 \%$ and European beech (Fagus sylvatica L.) $12 \%$ of all forests stands in the $1-20$ year age class, according to the 2012 National Forest Inventory (Thünen Institut 2014). Beech is the standard tree species used for forest conversion, in particular in Southern Germany, but also elsewhere (Hanewinkel et al. 2010). Currently, European beech is promoted due to its high resilience to disturbances, as the time series of 
the German Forest Survey show (Bayerisches Staatsministerium für Ernährung, Landwirtschaft und Forsten (StMELF) 2020; Bundesministerium für Ernährung und Landwirtschaft (BMEL) 2020). Additionally, scientists hope to find more drought resistant provenances (Jandl et al. 2019) that might prevail under future climatic conditions (Jandl et al. 2019). However, its sensitivity to climate change is still under debate (Rennenberg et al. 2004; Ammer et al. 2005; Geßler et al. 2006; Bolte et al. 2016). Therefore, large areas in Germany are covered with young to middle age Norway spruce and European beech forests which leaves forest enterprises with the question of how best to implement climate-adapted management. Mixed species stand types comprising spruce and beech in variable proportions are still a standard future forest type, frequently used in forest planning. Therefore, forest managers are interested in how silvicultural measures (i.e. stand types, thinned or unthinned, rotation length, how much of each stand type) could best adapt future forests also consisting of these species to climate change. An economic valuation of risks and ecosystem services connected to the cultivation of the two species might prove valuable for the German forestry sector.

We simulated four different tree species compositions for the two climate sites. The four compositions were: pure European beech, 50\% European beech and 50\% Norway spruce, $80 \%$ Norway spruce and 20\% European beech and pure Norway spruce. Those are common silvicultural options for forest stand composition. Both tree species are managed as monocultures and as mixed stands (Thünen Institut 2014). As European beech is considered an alternative to Norway spruce (see introduction), we simulated two stand types with an admixture of $20 \%$ and $50 \%$ of European beech to Norway spruce. We used the structural generator, STRUGEN (Pretzsch 1997) to create initial stands with an age of 30 to 40 years. For each stand, we simulated several thinning regimes. From the different thinning concepts, we selected for each stand the one with the highest financial return as an option for the optimisation algorithm. For stand types with a share of $100 \%$ or $50 \%$ European beech, we also included the alternative without thinning as an option for the model. Omitting thinnings is a management alternative often practiced by small-scale forest owners. Stands dominated by Norway spruce, however, were always thinned. We justify this with the higher vulnerability to windthrow of unthinned stands because they reach harvesting diameters later (Hanewinkel et al. 2015). We also varied rotation age for all stand types, with a conservative maximum age estimate and with maximised soil rent. The National Forest Inventory (NFI) in Germany for 2012 found that $30 \%$ of all stands of Norway spruce was older than 80 years, and 16\% were older than 100 years (Thünen Institut 2014). We concluded from this result that common rotation ages for Norway spruce are 80 to 100 years. For European beech, we found rotation ages to be higher. The NFI showed that $45 \%$ of all stands were older than 100 years and $31 \%$ older than 120 years. $19 \%$ of all stands of European beech in Germany were older than 140 years. Some forest managers seemed to choose shorter rotation ages, beginning the first harvests in stands of Norway spruce at the age of 60 years. A small proportion of forest owners manage their forests with longer rotation ages. From these findings and reflections, we decided to use a maximum rotation age of 120 years for Norway spruce in the model region Northeast High Plain with higher biomass productivity and 140 years for the region Lower Main Area with lower productivity. Maximum rotation age for European beech was 140 years. As a progressive alternative, we used a rotation age that maximises soil rent in the respective stand type. These rotation ages were in all cases considerably shorter (40 to 60 years) than the maximum rotation age. From now on, we refer to those as stand types with "short rotation". The simulation results were the standing volume of trees, thinning volume and volume of dead wood from trees that died of natural mortality. Overall, we simulated 12 stand types (Fig. 2).

\section{Sensitivity analysis: wood prices, regeneration costs and discount rate}

We varied different model parameters from the baseline parameters. First, we explored two different price settings. The ratio between the European beech and Norway spruce wood prices was changed by setting the wood prices for European beech to $150 \%$ and $200 \%$. We also tested the influence of an interest rate of $1.5 \%$ and $3.0 \%$ compared to the $2 \%$ baseline. Third, initial and rotation age dependent regeneration costs for European beech might lead to different results, as the investment cost ratios between the species vary. To illustrate, the younger the stands were at the time of the final harvest, the higher the costs for planting young trees due to the inability of younger trees to produce seedlings. Therefore, we created a scenario where European beech was planted at the beginning of the first rotation and when the rotation age fell below 100 years.

\section{Results}

\section{Forest enterprise composition}

Our results are portfolios of stand types for forest enterprises located in similar climatic regions to those investigated in our study. These portfolios show how our specific enterprises should allocate their area to different stand types with regard to the specific climate setting and the objectives considered. The optimised composition of the virtual forest 
Fig. 2 Forest stand types selected from the growth simulation as options for the optimisation algorithm

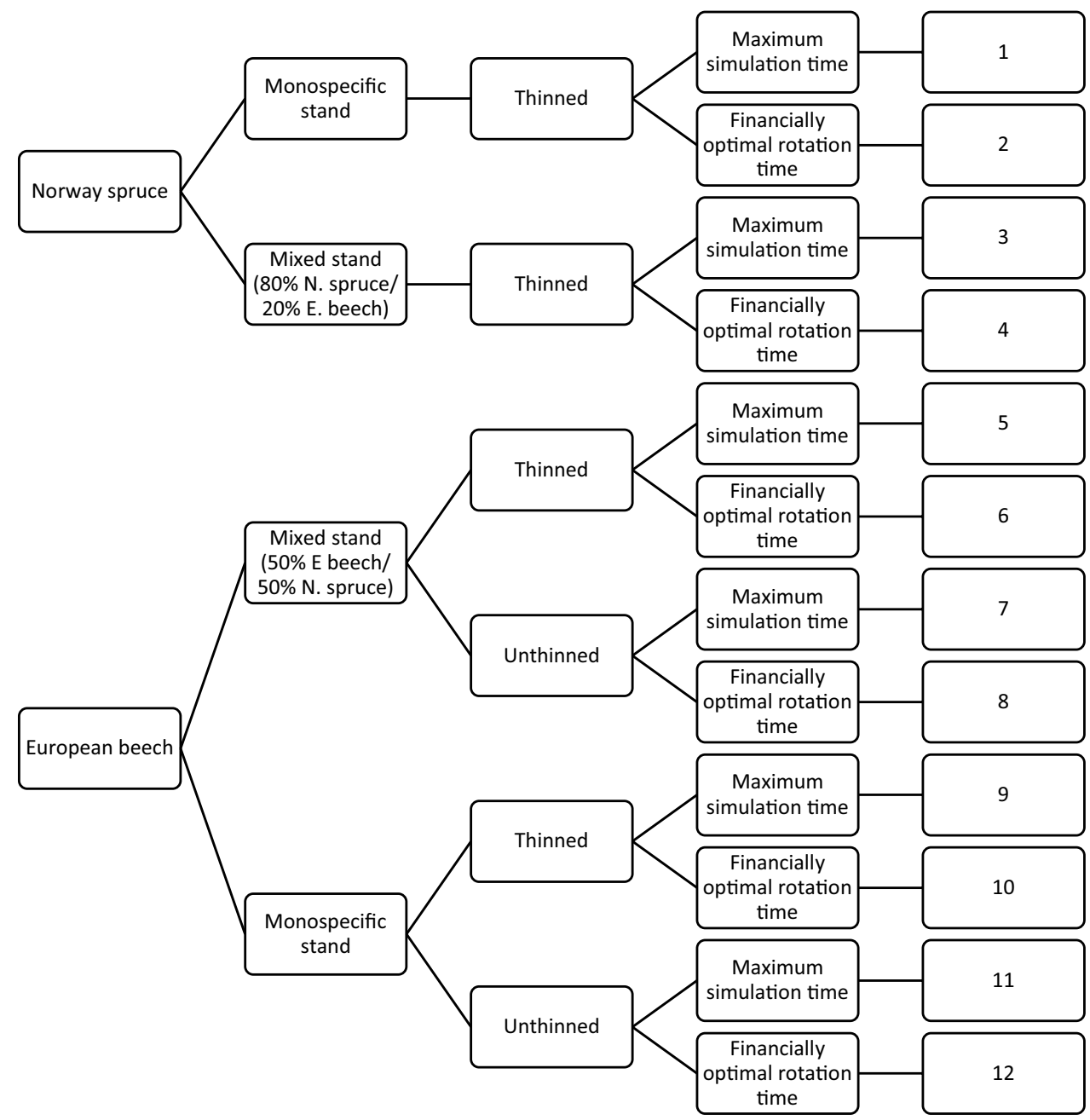

enterprises (Fig. 3) differed substantially, depending on the level of uncertainty, the climatic setting and the objectives.

\section{Influence of uncertainty}

Considering uncertainty led to increased portfolio diversification. The Shannon index for each scenario increased with increasing uncertainty level (Table 3 ), indicating that the forest portfolios became more diversified. At each level of uncertainty, $m$, the Shannon index was higher for the MultCool and MultWarm scenarios than under a single objective. As further characteristics, we calculated the share of spruce in the portfolio, the summed up proportions within mixed stands and monocultures. In the FinCool scenario, the relative share of Norway spruce in the forest enterprise declined from $91 \%$ at low uncertainty to $72 \%$ at larger uncertainty. In the other scenarios, the initially low (FinWarm, MultWarm) or medium (MultCool) values for the share of Norway spruce increased at higher levels of uncertainty. We observed the same for stand types with short rotation ages, because considering higher levels of uncertainty lead to more diversified portfolios. For the scenario MultWarm, the share of stand types with short rotation length was $61 \%$ at $m=1$ (which reflects the perspective of a forest manager with a low level of risk aversion) and $46 \%$ at $m=3$ (which reflects a highly risk-averse decision maker).

\section{Influence of climate change}

Under cooler climatic conditions (FinCool and MultCool scenarios), the share of spruce was highest, never falling below $50 \%$ except in the MultCool scenario at $m \leq 1$. In contrast, in the warm and dry climate of the FinWarm and MultWarm scenarios, European beech dominated the portfolios and Norway spruce never exceeded a share of $31 \%$. We did not observe an influence of climate conditions on the share of stand types with short rotation age.

\section{Influence of multifunctionality}

Considering multiple objectives led to more diversified forest compositions, underlined by higher values of the 


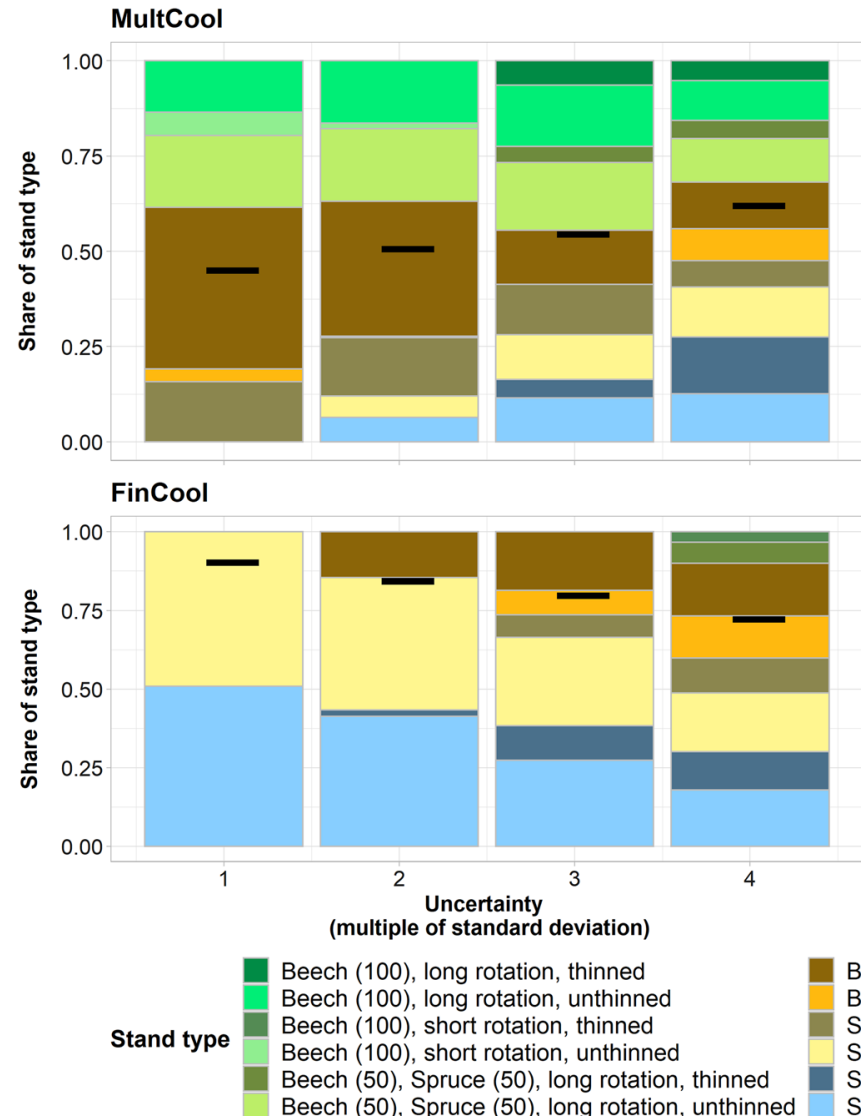

Fig. 3 Composition of the forest enterprise area for the four scenarios

Table 3 Shannon Index (Shannon's H) for the scenarios and different uncertainty factors

\begin{tabular}{lllll}
\hline Scenario & \multicolumn{4}{l}{ Uncertainty factor $(\mathrm{m})$} \\
\cline { 2 - 5 } & 1 & 2 & 3 & 4 \\
\hline FinCool & 0.69 & 1.09 & 1.66 & 1.99 \\
MultCool & 1.53 & 1.69 & 2.10 & 2.24 \\
FinWarm & 0.05 & 0.95 & 1.56 & 1.85 \\
MultWarm & 1.42 & 1.88 & 1.90 & 1.95 \\
\hline
\end{tabular}

Table 4 Return annuity (Euro $\mathrm{ha}^{-1} \mathrm{yr}^{-1}$ ) for the virtual forest enterprise (see Fig. 3)

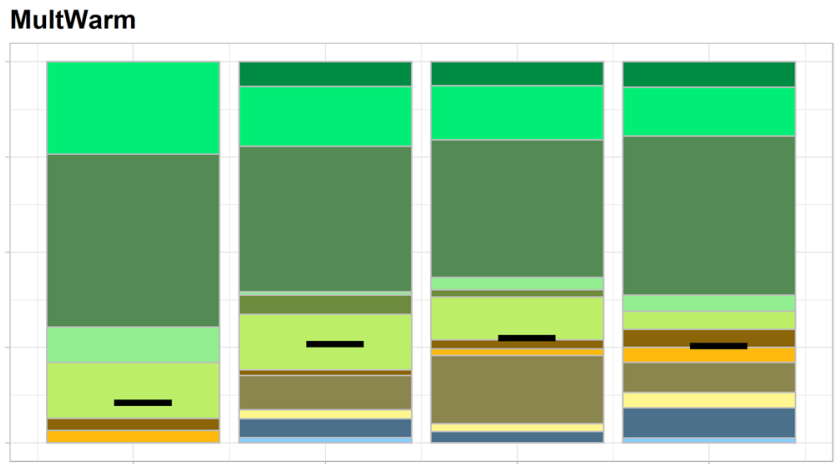

FinWarm

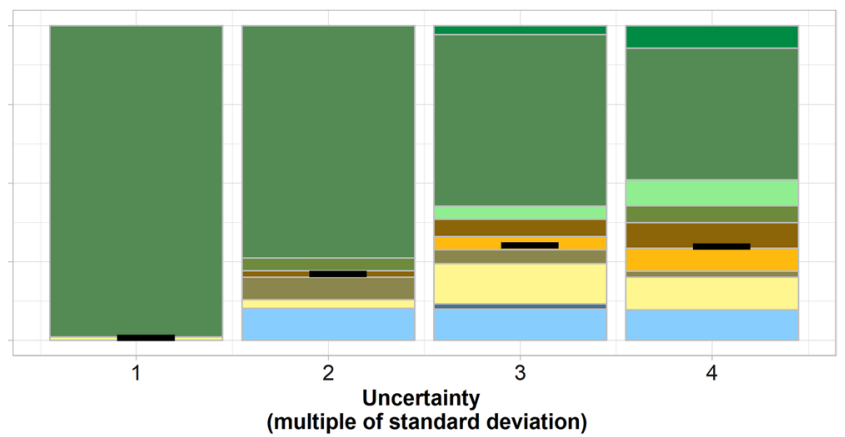

Beech (50), Spruce (50), short rotation, thinned Share of spruce Beech (50), Spruce (50), short rotation, unthinned

Spruce (80), Beech (20), long rotation, thinned

Spruce (80), Beech (20), short rotation, thinned

Spruce (100), long rotation, thinned

Spruce (100), short rotation, thinned highest in the scenarios FinCool and FinWarm, never falling below $78 \%$ and $85 \%$, respectively. For the scenarios MultCool and MultWarm, we observed more balanced portfolios regarding rotation length, with shares of stand types of short rotation age between 37 and $61 \%$.

\section{Premium for risk aversion}

Our results showed that higher precaution against uncertainties requires a financial premium (Table 4 and Appendix

\begin{tabular}{llllllll}
\hline Climatic scenario & \multicolumn{3}{l}{$\begin{array}{l}\text { Financial objective (FinCool and } \\
\end{array}$} & & \multicolumn{3}{l}{$\begin{array}{l}\text { Multiple objectives (MultCool } \\
\text { and MultWarm) }\end{array}$} \\
\cline { 2 - 3 } & $m=1$ & $m=3$ & Difference & & $m=1$ & $m=3$ & Difference \\
\hline Cool average precipitation & 237 & 218 & $-19(-8 \%)$ & & 152 & 155 & $+3(+2 \%)$ \\
Warm low precipitation & 68 & 63 & $-5(-7 \%)$ & & 50 & 51 & $+1(+2 \%)$ \\
\hline
\end{tabular}

Shannon index (Table 3). The portfolios of MultCool and MultWarm scenarios had slightly more balanced tree species shares. The change in objectives considerably influenced the share of stand types with short rotation ages. This was
Table 9). Annuities were 8\% lower for the FinCool scenario when the uncertainty factor $m$ was increased from 1 to 3 . In the climate change scenario for FinWarm, the absolute 
Table 5 Indicator values in the two climatic regions (uncertainty factor $\mathrm{m}=3$ )

\begin{tabular}{|c|c|c|c|c|c|c|}
\hline \multirow[t]{2}{*}{ Climatic scenario } & \multicolumn{3}{|l|}{ Objective } & \multicolumn{3}{|c|}{ Multiple Objectives (MultCool and MultWarm) } \\
\hline & $\begin{array}{l}\text { Financial return } \\
\left(\text { Euro } \mathrm{ha}^{-1} \mathrm{yr}^{-1} \text { ) }\right.\end{array}$ & $\begin{array}{l}\text { Carbon storage } \\
\left(\mathrm{tC} \mathrm{ha} \mathrm{ha}^{-1} \mathrm{yr}^{-1}\right)\end{array}$ & $\begin{array}{l}\text { Stability } \\
\text { (Probability to } \\
\text { reach rotation age) }\end{array}$ & $\begin{array}{l}\text { Financial return } \\
\left(\text { Euro } \mathrm{ha}^{-1} \mathrm{yr}^{-1}\right)\end{array}$ & $\begin{array}{l}\text { Carbon storage } \\
\left(\mathrm{tC} \mathrm{ha}^{-1} \mathrm{yr}^{-1}\right)\end{array}$ & $\begin{array}{l}\text { Stability } \\
\text { (Probability to } \\
\text { reach rotation } \\
\text { age) }\end{array}$ \\
\hline Cool average precipitation & 218 & 12.3 & 0.82 & 155 & 17.5 & 0.76 \\
\hline Warm Low precipitation & 63 & 7.24 & 0.80 & 51 & 10.7 & 0.68 \\
\hline
\end{tabular}

Table 6 Climate change effect on the indicator values (relative level in the analogous region) at an uncertainty factor of $\mathrm{m}=3$

\begin{tabular}{llllllll}
\hline Indicator & \multicolumn{2}{l}{ Financial objective (fincool-finwarm) } & & \multicolumn{2}{l}{ Multiple objectives (multcool—mult warm) } \\
\cline { 2 - 3 } & Financial return & Carbon storage & Stability & & Financial return & Carbon storage & Stability \\
\hline Relative level in the analogous region & $29 \%$ & $59 \%$ & $98 \%$ & & $33 \%$ & $61 \%$ & $89 \%$ \\
\hline
\end{tabular}

premium was lower, as the level of income was already diminished by considering multiple objectives. In relative terms, the risk premium was at $7 \%$. The financial risk premium was only apparent when a single objective was valid. Under multiple objectives, however, we observed a very small positive increase of financial return. Enterprises with multiple objectives also had to accept lower portfolio performance for the other objectives (Appendix Table 9). The (non-financial) risk premium for the MultWarm enterprise was below $1 \%$ for carbon storage and at $14 \%$ for stability. For the scenario MultCool, we observed a premium of $6 \%$ for stability, but higher carbon storage $(+8 \%)$.

\section{Climate change effects}

The comparison of analogue climate regions allowed us to estimate the influence of climate change on ecosystem service provision. Table 5 provides a comprehensive look at the indicator values of all ecosystem services. It distinguishes between our two climatic regions and different objectives (detailed in the next section).

Climatic conditions influenced ecosystem service provisioning. We observed lower financial return $(-71 \%)$, carbon storage $(-41 \%)$ and stability $(-2 \%)$ for the scenarios FinWarm and MultWarm compared to FinCool and MultCool. Considering financial return, however, led to tradeoffs for carbon storage. Carbon storage was $42 \%$ lower in the FinCool scenario and $48 \%$ lower in the FinWarm scenario compared to the MultCool and MultWarm scenarios. For stability, we observed that the probability to reach the planned rotation age was higher in the FinCool and FinWarm scenarios. Our forest enterprises showed vastly different indicator levels (Table 6) under the warm scenario with low precipitation.
Table 7 Relative level (\%) of return (annuity) if the FinCool and MultCool enterprises do not to adapt area composition to climate change

\begin{tabular}{lllll}
\hline Scenarios compared & \multicolumn{5}{l}{ Uncertainty factor $(m)$} \\
\cline { 2 - 5 } & $1(\%)$ & $2(\%)$ & $3(\%)$ & $4(\%)$ \\
\hline FinCool - FinWarm & 81 & 88 & 86 & 89 \\
MultCool-MultWarm & 96 & 92 & 86 & 85 \\
\hline
\end{tabular}

The financial return declined to a level of around one third for both scenarios. The storage of carbon dropped to a level of $59 \%$ and $61 \%$ respective to the number of objectives. Stability declined to a level of $98 \%$ and $89 \%$. Due to the selection of stand types with a high share of European beech and low rotation ages, the influence of climate change on this indicator was comparatively low. The more diversified multifunctional forest enterprises buffered their losses to a slightly higher extent than the specialised forest enterprises. The relative level of the indicator values between the cool and warm regions was only 4 percentage points for financial return, and 2 percentage points higher for carbon storage and stability in multifunctional forests.

\section{Financial effects of adaptation}

Table 7 shows the results of FinCool and MultCool scenarios that refrain from silvicultural adaptation measures. Relative levels of financial return below $100 \%$ indicate that adaptive actions in forest management are favourable.

The FinCool scenario had higher losses in financial return without silvicultural measures against climate change than the MultCool scenario. This was valid at a low level of uncertainty ( $m$ 3) where the forest area was less diversified. At $m>3$, the returns were more stable in scenario FinCool 
compared to the MultCool scenario. However, the increased diversification of the MultCool scenario served as protection against climate change at lower levels of uncertainty.

\section{Financial premium for multifunctionality}

One of our research objectives was the influence of forest multifunctionality on ecosystem services. Table 4 compares the financial returns of an economic and a multifunctional scenario. For the scenario FinCool, the financial returns dropped to $71 \%$ when objectives were changed to those of the MultCool scenario. Thus, a premium arose for multifunctionality of 85 Euro $\mathrm{ha}^{-1} \mathrm{yr}^{-1}$. The multifunctionality premium under warmer climate conditions (FinWarm to MultWarm) was 18 Euro $\mathrm{ha}^{-1} \mathrm{yr}^{-1}$, which was a relative reduction to a level of $81 \%$. The relative reduction of the financial return was, thus, slightly lower under warmer climatic conditions. If the decision maker's preferences included all three indicators, the financial return of MultCool, MultWarm scenarios was lower compared to the FinCool and FinWarm scenarios.

\section{Discussion}

Our study presents the first analysis of climate change impacts on tree species and stand type selection with a new combination of robust and multi-criteria optimisation. Our results are general in character and would need adaptation to specific forest enterprises, which are likely to include other tree species. Our assumptions about environmental conditions as well as our approach to robustness facilitate general conclusions about the advantages and costs of silvicultural diversification to buffer against risk and secure multiple forest functions. Addressing the aspect of a function premium is novel. From our Southeast German scenarios, we deduce recommendations for broader management strategies to adapt forests to climate change, considering uncertainty and multiple objectives. Our results show diversification to be a promising strategy that nevertheless involves opportunity costs. Here, the diversification is not limited to mixing tree species, but also pertains to mixing rotation times as well as thinned and unthinned stands. The study expands on existing economic models of tree species and stand type selection. Furthermore, we stepped away from the ex post evaluation of pre-defined silvicultural scenarios and ex ante selected the optimal combination of a multitude of options. The approach offers orientation on both decision makers' preferences as well as their level of risk aversion. We address climate change impacts with the concept of analogous climatic regions, estimating the influence of future climatic conditions on ecosystem service provisioning. Thus, we aim to remedy the gap between knowledge of climate change consequences and adequate adaptation strategy proposals (Jandl et al. 2019).

\section{Influence of considering uncertainty}

Optimising forest enterprise composition under increasing uncertainty (research question 1) led to diversified forests. To account for uncertainty, the optimal composition of the forest area included both tree species, not only the more resistant European beech. This can be seen, for example, in the rising relative share of Norway spruce, also as a monoculture, in the enterprise portfolios of the FinWarm and MultWarm scenarios. The robust optimisation algorithm took into account that in case of a disturbance, the low financial return of European beech (see Table 8) declined even more and therefore added stand types with Norway spruce to stabilise the indicator's performance. Thus, we confirmed previous studies (Augustynczik et al. 2018) and expanded on them by including multiple objectives and climate change. We found that for highly risk-averse forest owners, even under a purely financial objective, robust optimisation required intensified mixing of silvicultural strategies. Therefore, portfolio composition also served as a guarantee for multifunctionality. The downside of safeguarding against uncertainty is the risk premium forest owners would need to accept. As one of the first studies in forestry of this kind, we emphasise this aspect. Previous studies focused on risk aversion, especially with regard to resistance against natural threats (Schütz et al. 2006; Albert et al. 2017) and did not address the costs of this adaptation. The risk premium is relatively low, however, compared to the cost of multifunctionality or climate change. We explain this with high or increasing shares of spruce even under very high uncertainty. This contrasts with other studies that found Norway spruce to be highly prone to natural risks (Griess et al. 2012). Our model also considered that European beech is facing climate change-induced risks. As such, we included uncertain indicator values of ecosystem services for European beech. In this case, the uncertainty set displayed scenarios with only pessimistic indicator values for European beech and the robust reference point method searched for feasible solutions. We have applied the strictest robustness model among the forest science studies in robust optimisation we know. Using box-uncertainty spaces, we do not assume a stochastic nature of the perturbations considered. Rather we follow an approach characterised by Ben-Tal et al. (2009) as "uncertain-but-bounded". An alternative would be to use "techniques that are capable to utilise, to some extent, knowledge of the stochastic nature of data perturbations when building uncertainty-immunised solutions." (Ben-Tal et al. 2009). For example, in their robust optimisation studies Augustynczik et al. (2018) and Augustynczik et al. (2020) adopted a Bernstein approximation to implement their 
uncertainty spaces, thus applying an approach assuming a behaviour of the input coefficients (for example net present values) as random variables. Consequently, those studies implied a stochastic nature with their uncertainty model. In contrast to the approaches making stochastic assumptions, our approach might be less efficient, but not less robust.

\section{Climate change impacts}

Concerning our research question 2), we found that adaptation measures of forest enterprises should include the selection of tree species, the tree species mixture as well as the length of rotation age and treatment. These are active adaptation measures in forest management (Bolte et al. 2010). An example of a climate change adaptation strategy that we observed is the optimisation algorithm reducing rotation age in the RCP 8.5 scenarios (FinWarm, MultWarm). The shorter rotation stand types achieved a higher and more stable indicator value for ecosystem stability compared to the cooler climate. We conclude that diversification with the three aforementioned strategies can provide protection against climate change and losses in ecosystem service provisioning in forestry. However, depending on the degree of climate change, compensation will only be partial. Our model calculates a severe decline in soil rent for the climate change scenario. Hanewinkel et al. (2013) modelled that climate change will lead to a shift in tree species suitability and productivity. Both effects will reduce the soil expectation value of forests in Europe by around 36\% for a pessimistic climate change scenario. We calculated higher financial losses and additional losses for non-financial ecosystem services. Mina et al. (2017) analysed climate change impacts on ecosystem services in Alpine Regions in Europe and found that timber production and carbon storage were negatively influenced in a nearby case study region. We confirm these results, but additionally and systematically searched for a specific combination of stand types. This identified measures to retain carbon storage (Ontl et al. 2020). Thus, our study differs from previous approaches that performed $e x$ post evaluations of silvicultural scenarios. Our methodology actively selected combinations of 12 different silvicultural management options to achieve single or multiple objectives ex ante. The approach therefore presents a technical alternative that can be extended to other stand types.

Our approach to consider climate change is coherent with our strict robustness model. We assume the worst IPCC scenario and set our starting point to the future in a steady state climate. Therefore, our recommendations for management strategies are valid for the climatic conditions in the future. Climate change, however is a dynamic process, and forest managers could use new findings to gradually adjust these management strategies. Radke et al. (2020) recommended dynamic adaptive strategies to account for climate change-induced deep uncertainty. They created a wide range of scenarios, amongst those also climate scenarios for a stand of European beech in Southwest Germany. With those scenarios, they tested a pre-defined static management strategy's robustness and identified key uncertainties that heavily influenced the performance. A gradual adaptation to climate change might be able to avoid the failing of static management strategies. Initial assumptions about future model parameters might prove wrong and dynamic management strategies using the identified critical uncertainties could mitigate suboptimal past decisions. This could be a promising and more efficient approach to lessen the very conservative nature of our robust model. Our solutions, however, were valid for a wide range of potential outcomes, thus guaranteeing robustness. We referred to Möhring and Rüping (2008) to justify a static approach because stand type selection cannot easily be adapted upon receiving new information, unlike silvicultural treatment of an existing stand or agricultural land-use types.

\section{Influence of multiple objectives}

Depending on the objectives (research question 3), the optimisation algorithm selected a different combination of stand types. Mixing the two tree species within a stand (and not only mixing spruce and beech monocultures at the forest enterprise level), was observed as a management strategy to consider multifunctionality and uncertainty in both climate scenarios. Shannon's H values (Table 3) underlined this effect at higher levels of uncertainty. On average, mixed stands provided lower levels of the single indicator values compared to the (pure) stand type. This could be observed for the financial return and ecosystem stability (Table 8), for example. However, mixed stands provided higher worst-case levels for all ecosystem services. We also found that the proportion of mixed stands was lower in the analogous climate region. The Shannon diversity tended to decline in the warmer climate regions. This underlined that climate change limited the opportunities of our virtual forest enterprise to adapt to climate change, because more climate sensitive stand types were no longer suitable as diversification components. In the warmer climate region, ecosystem service provisioning declined and its uncertainty increased-especially for stand types dominated by Norway spruce and those with long rotation ages. Therefore, the optimisation model preferred the smaller number of stand types with a lower standard deviation in indicator values. The sensitivity analysis in our study underlined that the objectives and their number wielded considerably more influence than other considered parameters. Our study also extended previous approaches that considered decision makers' objectives, but these approaches disregarded either uncertainty or climate change (Nordström et al. 2013; Diaz-Balteiro et al. 2017a; 
Gosling et al. 2020; Knoke et al. 2020). Nordström et al. (2013) showed that decision makers evaluated silvicultural scenarios differently because they weighed objectives differently, but did not analyse the influence of climate change or other sources of uncertainty. Knoke et al. (2020) concentrated on the effect of multi-criteria decision making on tropical deforestation. Gosling et al. (2020) focused on integrating uncertainty in multi-criteria land-use optimisation in Panama. Both studies showed that managing uncertainty for several objectives leads to more highly diversified landscapes. However, all of the aforementioned studies neglected climate change and its influence on both growth and the survival of agricultural crops and forest trees. Our results, however, are also valid for uncertain future climatic conditions and for situations where information about the objectives' values is not clear. Forest owners will have to accept a multifunctionality premium when striving for multiple goals. This is a trade-off for receiving a higher performance of, in our case two other ecosystem services. Our results further indicate that adaptation measures to provision multiple ecosystem services serve as a protection against a risk premium. As the area of a multifunctional forest had a higher diversification, considering more uncertainty led to even higher returns in our case. We explain this with interactions between the three indicator variables and their variation. The distance $\beta$ for carbon had a restricting effect here, so the algorithm selected higher shares of Norway spruce to avoid diminishing carbon storage. Conversely, this stabilised financial return as Norway spruce generates higher cash flows in shorter rotation periods.

The equal weighting of all forest ecosystem services is a novelty of our study. This considers all objectives as indispensable. Introducing priorities for single ecosystem services would have changed forest enterprise portfolios considerably as the comparison between the financial and multi-criteria scenarios show (Fig. 3). However, ranking ecosystem services would contradict the robust approach we chose. We specifically assumed that we do not know the decision maker's future preferences for the ecosystem services. Our solutions represent portfolios which make the smallest possible concession towards losses of objectives. The approach can integrate both market and non-market values and can thus refrain from valuating these services monetarily. Therefore, the concept of strong sustainability is applied (Neumayer 2013). Bateman et al. (2013) optimised agricultural land-use for the UK and assigned market values to all landscape services. As a result, the land-use type with the highest marketable value dominates the agricultural landscape. To secure valuable landscape services with low marketable value, for example biodiversity, Bateman et al. (2013) had to impose restrictions. Our study, in contrast, overcomes this disadvantage and secures a minimum indicator level for all objectives, avoiding additional restrictions.

\section{Critical discussion of the model}

Considering only European beech and Norway spruce restricts the optimisation's results because we lack a larger number of stand types (Pretzsch 2005; Liang et al. 2016). Previous research showed that the marginal gain of ecosystem functions, such as biomass production, may decline with an increasing number of mixed tree species (Pretzsch 2005; Liang et al. 2016). Future studies that include more tree species with a wider range of ecosystem service provisioning could prove valuable despite this saturation effect. Nevertheless, due to the complexity of tree species interaction and data acquisition, other studies on tree species selection were also limited to a few tree species (for example Felton et al. 2010; Thiele et al. 2017). Although our study is limited to only two important tree species, we still consider the results to be generalisable. Norway spruce stood as an archetype for a tree species with high financial performance and susceptibility to climate change. In contrast, European beech was an archetype for species with lower financial performance-at least for the past climate-higher resistance and resilience to natural disturbances. Considering the characteristics of these archetypes, forest managers could evaluate other tree species and assess their share in the forest portfolios. For example, Douglas fir (Pseudotsuga menziesii (Mirb.) Franco) might partly replace Norway spruce due to its higher stability and financial performance, whereas pedunculate oak (Quercus robur L.) might complement the portfolios as an alternative to European beech considering ecosystem stability. For future research, it would also be interesting to investigate stands dominated by European beech with an admixture of conifers below $50 \%$. Our robust method is basically able to include more options into the optimisation algorithm of forest area composition, as Uhde et al. (2017) underlined. Although we chose socio-economic and socio-ecological indicator values and cover different aspects of sustainability, a multifunctional approach could be extended to more than three ecosystem services. The reference point method uses normalised indicator values without units and can include a larger number of objectives. Knoke et al. (2016) showed that repeatedly including eight or more random indicators stabilises landscape portfolio composition, an observation they call the "multifunctionality effect". In our study, the multiobjective optimisation algorithm includes stand types with different tree species compositions or rotation ages. This highly diversified enterprise might provide a higher number of ecosystem services we considered and might compensate for the small number of indicators in our study.

Our enterprise area includes both mixed and monospecific stands after optimisation for multiple criteria. This contrasts with studies that found mixed stands often provide higher levels of ecosystem services than monocultures (Mori et al. 2017). Monocultures, as our enterprises with financial 
objectives show, provide the highest values for single ecosystem services. At a low level of risk aversion, the optimisation algorithm considers mixing monocultures on the enterprise level as an alternative to solely combining mixed stand types. With larger uncertainty spaces, monospecific stand types are still part of the enterprise's portfolio but in combination with mixed species stands. Thus, the concept of mixed forests that provide multiple ecosystem services on the stand level (Pretzsch et al. 2017) can be transferred to a higher spatial level. On the landscape level, the same ecosystem services could be provisioned by a combination of monocultures. This might be an alternative to mixed forest stands where silvicultural or other obstacles prevent (smallscale) forest owners from establishing mixed stands.

Apart from addressing climate change and decision makers' objectives, we also included bio-physical interactions in our model. Coll et al. (2018) stated that the effects of mixing tree species on the economic outcome are still not comprehensively known. Our study found one effect to be increased stability in mixed forests. The integration of survival functions with the shares of the tree species as covariates addresses this research gap. Previous studies (Neuner et al. 2015; Paul et al. 2019) already integrated survival functions in economic models. Paul et al. (2019) optimised tree species composition, even for different climate change scenarios. However, these are stochastic models that include only level 2 uncertainty (Walker et al. 2013) where probabilities of occurrence for events must be known. This article considers the higher level 4 uncertainty and searches for solutions for scenarios with unknown probability of occurrence. Furthermore, our growth simulation of the stand types differentiates between mixtures. Therefore, we expand on approaches that use yield tables of monospecific stands and refer to growth functions to simulate effects of tree species diversity on productivity (García-Robredo 2018).

\section{Conclusions}

Our results provide recommendations for long-term goals for tree species selection in a Southeast German forest enterprise. On a general level, we derive silvicultural management strategies to deal with uncertainty, demand for multifunctional forestry and climate change. Our results have a rather general character and need adjustment when applying them to a specific forest enterprise. We have not derived exact shares of certain forest stand types valid for any enterprise. Our setting disregards, for example, soil conditions which might play an important role for water availability for the trees. However, one could tailor this approach to a specific forest enterprise, as for example done by Neuner et al. (2013), while considering a stochastic (not robust) portfolio model for financial objectives. When we included uncertainty in a virtual forest enterprise's decision about silvicultural adaptation strategies, diversification intensified. Climate change altered the optimal tree species composition of our virtual forest enterprise. Our approach combines tree species selection and mixing, treatment and different rotation ages as silvicultural strategies to mitigate climate change. However, there is still uncertainty on how mixed forest stands, as described in our study, will perform long-term in terms of productivity or resistance against hazards under climate change. But even under high uncertainty, we conclude that strategies to adapt to climate change can financially buffer the consequences of higher temperature and lower precipitation to a certain extent. Nevertheless, our simulation cannot find a compensatory effect to adaptation measures. The loss in productivity and the higher susceptibility towards hazards of Norway spruce, one of the main tree species in Germany, will negatively affect the income of public and private forest owners. In addition, European beech, the most common tree species to replace Norway spruce, seems to be limited in its potential to mitigate climate change. Further silvicultural strategies and expanding the options of stand types, especially concerning the tree species, for the optimisation could provide potential to mitigate climate change. If we consider the characteristics of our tree species as archetypes, species such as Douglas fir or silver fir (Abies alba Mill.) could be alternatives to stabilise survival probability, carbon storage and financial return under climate change. However, small-scale forest owners are often limited in their choice of silvicultural options. A solution to a risk-averse society (e.g. communal municipality) with many small-scale forest owners could be to have policy-makers set incentives to diversify on a level beyond the single forest stand. Establishing and managing different monospecific stand types might help small-scale forest owners to overcome obstacles like deer browsing, available space for planting trees, etc. Mixed forests would then consist of monospecific and mixed forest stands on a municipal or landscape level.

\section{Appendix}

See Tables 8 and 9. 


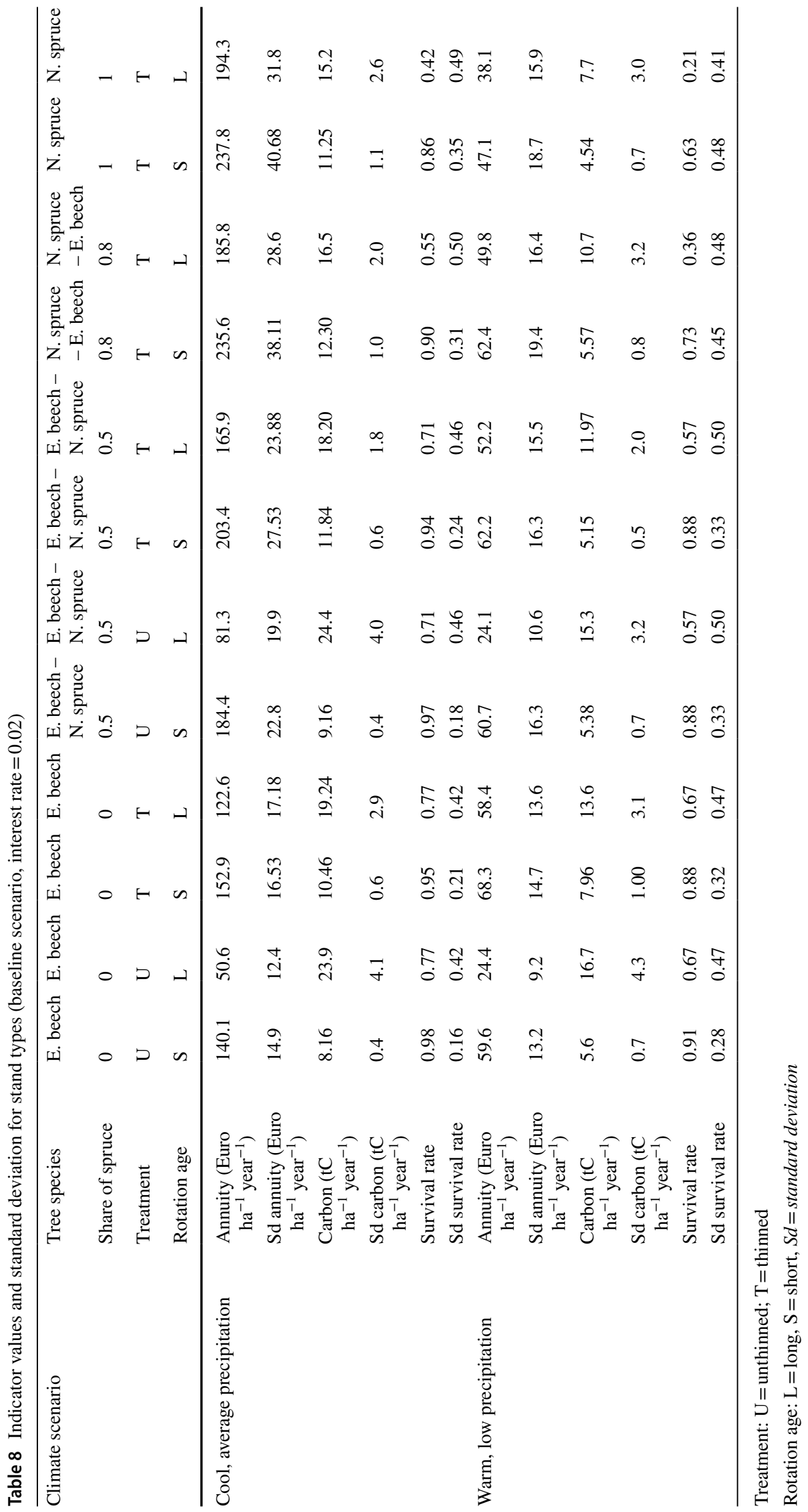


Table 9 Performance of optimised portfolios

\begin{tabular}{|c|c|c|c|c|c|c|c|c|c|}
\hline \multirow[t]{2}{*}{ Climate scenario } & \multirow[t]{2}{*}{ Indicator } & \multicolumn{8}{|c|}{ Uncertainty factor $m$} \\
\hline & & 0.5 & 1 & 1.5 & 2 & 2.5 & 3 & 3.5 & 4 \\
\hline \multicolumn{10}{|l|}{ Multifunctional objective } \\
\hline \multirow[t]{3}{*}{ Cool, average precipitation } & Annuity (Euro $\mathrm{ha}^{-1} \mathrm{a}^{-1}$ ) & 154 & 152 & 157 & 155 & 154 & 155 & 160 & 172 \\
\hline & Carbon storage $\left(\mathrm{Ct} \mathrm{ha}^{-1} \mathrm{a}^{-1}\right)$ & 16.6 & 16.3 & 16.6 & 16.9 & 17.2 & 17.5 & 17.0 & 15.8 \\
\hline & Probability of survival until rotation age & 0.85 & 0.81 & 0.80 & 0.80 & 0.79 & 0.76 & 0.76 & 0.76 \\
\hline \multirow[t]{3}{*}{ Warm, low precipitation } & Annuity (Euro ha $\left.\mathrm{ha}^{-1} \mathrm{a}^{-1}\right)$ & 50 & 50 & 53 & 50 & 50 & 51 & 53 & 55 \\
\hline & Carbon storage $\left(\mathrm{Ct} \mathrm{ha}^{-1} \mathrm{a}^{-1}\right)$ & 11.7 & 10.8 & 10.8 & 11.1 & 10.9 & 10.7 & 10.4 & 9.5 \\
\hline & Probability of survival until rotation age & 0.79 & 0.79 & 0.79 & 0.69 & 0.69 & 0.68 & 0.71 & 0.72 \\
\hline \multicolumn{10}{|l|}{ Financial objective } \\
\hline \multirow[t]{3}{*}{ Cool, average precipitation } & Annuity (Euro ha $\mathrm{ha}^{-1} \mathrm{a}^{-1}$ ) & 237 & 237 & 236 & 231 & 227 & 218 & 213 & 206 \\
\hline & Carbon storage $\left(\mathrm{Ct} \mathrm{ha}^{-1} \mathrm{a}^{-1}\right)$ & 11.7 & 11.8 & 11.8 & 11.9 & 12.2 & 12.3 & 12.5 & 12.8 \\
\hline & Probability of survival until rotation age & 0.87 & 0.88 & 0.88 & 0.88 & 0.85 & 0.82 & 0.81 & 0.80 \\
\hline \multirow[t]{3}{*}{ Warm, low precipitation } & Annuity (Euro $\mathrm{ha}^{-1} \mathrm{a}^{-1}$ ) & 68 & 68 & 66 & 64 & 63 & 63 & 62 & 62 \\
\hline & Carbon storage $\left(\mathrm{Ct} \mathrm{ha}^{-1} \mathrm{a}^{-1}\right)$ & 7.9 & 7.9 & 7.5 & 7.9 & 7.4 & 7.2 & 7.2 & 7.5 \\
\hline & Probability of survival until rotation age & 0.88 & 0.88 & 0.86 & 0.80 & 0.78 & 0.80 & 0.81 & 0.80 \\
\hline
\end{tabular}

Supplementary Information The online version contains supplementary material available at https://doi.org/10.1007/s10342-021-01391-y.

Acknowledgements The authors would like to thank Alena Chilian and Juanita Schmidhammer for language editing and two anonymous reviewers for their comments, which helped to improve the overall quality of the manuscript.

Authors' contributions S.F. and T.K. designed the research layout, T.H. and H.P. supported the study with growth simulations. S.F. drafted the manuscript. All authors discussed results and conclusions and contributed to writing the final manuscript.

Funding Open Access funding enabled and organized by Projekt DEAL. The Bavarian State Ministry of Food, Agriculture and Forestry (grant number H10) funded this study.

\section{Declarations}

Conflict of interest The authors declare that they have no conflict of interest.

Consent for publication Authors approved the version to be published and agree to be accountable for all aspects of the work.

Open Access This article is licensed under a Creative Commons Attribution 4.0 International License, which permits use, sharing, adaptation, distribution and reproduction in any medium or format, as long as you give appropriate credit to the original author(s) and the source, provide a link to the Creative Commons licence, and indicate if changes were made. The images or other third party material in this article are included in the article's Creative Commons licence, unless indicated otherwise in a credit line to the material. If material is not included in the article's Creative Commons licence and your intended use is not permitted by statutory regulation or exceeds the permitted use, you will need to obtain permission directly from the copyright holder. To view a copy of this licence, visit http://creativecommons.org/licenses/by/4.0/.

\section{References}

Albert M, Nagel R-V, Nuske R et al (2017) Tree species selection in the face of drought risk-uncertainty in forest planning. Forests $8: 363$

Allen CD, Breshears DD, McDowell NG (2015) On underestimation of global vulnerability to tree mortality and forest die-off from hotter drought in the Anthropocene. Ecosphere 6:1-55

Ammer C, Bickel E, Kölling C (2008) Converting Norway spruce stands with beech - a review of arguments and techniques. Aust J For Sci 125:3-26

Ammer C, Borchert H, Brosinger F et al (2005) Zur Zukunft der Buche (Fagus sylvatica L.) in Mitteleuropa - kritische Anmerkungen zu einem Beitrag von Rennenberg et al. (2004). Allgemeine Forst und Jagdzeitung 176:60-67

Andersson E, Keskitalo EC, Bergstén S (2018) In the eye of the storm: adaptation logics of forest owners in management and planning in Swedish areas. Scand J for Res 33:800-808

Araújo MB, Alagador D, Cabeza M et al (2011) Climate change threatens European conservation areas. Ecol Lett 14:484-492

Augustynczik AL, Gutsch M, Basile M et al (2020) Socially optimal forest management and biodiversity conservation in temperate forests under climate change. Ecol Econ 169:106504

Augustynczik AL, Yousefpour R, Hanewinkel M (2018) Multiple uncertainties require a change of conservation practices for saproxylic beetles in managed temperate forests. Sci Rep 8:14964

Bayerische Staatsforstverwaltung/ Bayerische Staatsforsten. (1976 2015) Holzeinschlag- und Holzpreisstatistik für den Staatswald in Bayern

Bayerisches Staatsministerium für Ernährung, Landwirtschaft und Forsten (StMELF). (2020) Waldbericht 2020. Forest Report 2020 (in German), München

Ben-Tal A, Nemirovski A (1999) Robust solutions of uncertain linear programs. Oper Res Lett 25:1-13

Ben-Tal A, Nemirovski A, El Ghaoui L (2009) Robust optimization. Princeton University Press, Princeton

Biber P, Borges J, Moshammer R et al (2015) How sensitive are ecosystem services in European forest landscapes to silvicultural treatment? Forests 6:1666-1695 
Blanco V, Brown C, Rounsevell M (2015) Characterising forest owners through their objectives, attributes and management strategies. Eur J Forest Res 134:1027-1041

Bolte A, Ammer C, Löf M et al (2010) Adaptive forest management: a prerequisite for sustainable forestry in the face of climate change. In: Spathelf $P$ (ed) Sustainable forest management in a changing world: a European perspective. Springer, Dordrecht, pp 115-139

Bolte A, Czajkowski T, Cocozza C et al (2016) Desiccation and mortality dynamics in seedlings of different european beech (Fagus sylvatica L.) populations under extreme drought conditions. Front Plant Sci 7:751

Brandl S, Paul C, Knoke T et al (2020) The influence of climate and management on survival probability for Germany's most important tree species. For Ecol Manag 458:117652

Bullard SH, Straka TJ (2011) Basic concepts in forest valuation and investment analysis, 3rd edn. Forestry Suppliers Inc, Jackson, MS

Bundesministerium für Ernährung und Landwirtschaft (BMEL). (2019) Deutschlands Wald im Klimawandel - Eckpunkte und Maßnahmen. Discussion Paper for the National Forest Summit.

Bundesministerium für Ernährung und Landwirtschaft (BMEL). (2020) Ergebnisse der Waldzustandserhebung 2019. Results of the Forest Crown Survey (in German).

Buras A, Rammig A, Zang CS (2019) Quantifying impacts of the drought 2018 on European ecosystems in comparison to 2003

Coll L, Ameztegui A, Collet C et al (2018) Knowledge gaps about mixed forests. what do European forest managers want to know and what answers can science provide? For Ecol Manage 407:106-115

Creutzburg MK, Scheller RM, Lucash MS et al (2017) Forest management scenarios in a changing climate: trade-offs between carbon, timber, and old forest. Ecol Appl 27:503-518

Czech Statistical Office (2019) Salvage felling. Time series 2004 2018. https://www.czso.cz/documents/10180/91232997/10000 4192k211.pdf/f7e57c7f-c230-457e-94e0-8998d298e99a?versi on $=1.0$

Davis MB, Shaw RG (2001) Range shifts and adaptive responses to Quaternary climate change. Science (New York, N.Y.) 292:673-679

von Detten R, Hanewinkel M (2017) Strategies of handling risk and uncertainty in forest management in central Europe. Curr Forestry Rep 3:60-73

Diaz-Balteiro L, Alonso R, Martínez-Jaúregui M et al (2017a) Selecting the best forest management alternative by aggregating ecosystem services indicators over time: a case study in central Spain. Ecol Ind 72:322-329

Diaz-Balteiro L, Belavenutti P, Ezquerro M et al (2018) Measuring the sustainability of a natural system by using multi-criteria distance function methods: some critical issues. J Environ Manage 214:197-203

Diaz-Balteiro L, González-Pachón J, Romero C (2017b) Measuring systems sustainability with multi-criteria methods: a critical review. Eur J Oper Res 258:607-616

Diaz-Balteiro L, Romero C (2007) Multiple criteria decision-making in forest planning: recent results and current challenges. In: Weintraub A, Bjørndal T, Epstein R et al (eds) Handbook Of operations research in natural resources. Springer Science+Business Media LLC, Boston, MA, pp 473-488

Dieter M (2001) Land expectation values for spruce and beech calculated with Monte Carlo modelling techniques. For Policy Econ 2:157-166. http://www.sciencedirect.com/science/article/pii/ S1389934101000454

Duncker PS, Raulund-Rasmussen K, Gundersen P et al (2012) How forest management affects ecosystem services, including timber production and economic return: synergies and trade-offs. Ecol Soc 17
DWD. (2020) Nationaler Klimareport. Klima - Gestern, heute und in der Zukunft.

Eggers J, Holmgren S, Nordström E-M et al (2019) Balancing different forest values: evaluation of forest management scenarios in a multi-criteria decision analysis framework. For Policy Econ 103:55-69

Engelhard RJ, Anderson WC. (1983) A method of assessing risk in forestry investments, New Orleans, LA

Estrella R, Cattrysse D, van Orshoven J (2014) Comparison of three ideal point-based multi-criteria decision methods for afforestation planning. Forests 5:3222-3240

Falk W, Hempelmann N (2013) Species favourability shift in europe due to climate change: a case study for Fagus sylvatica L. and Picea abies (L.) Karst. based on an ensemble of climate models. J Climatol 2013:1-18

Faustmann M (1849) Berechnung des Werthes, welchen Waldboden, sowie nocht nicht haubare Waldbestände für die Waldwirthschaft haben. Allgemeine Forst- und Jagdzeitung, 441-455

Felton A, Lindbladh M, Brunet J et al (2010) Replacing coniferous monocultures with mixed-species production stands: an assessment of the potential benefits for forest biodiversity in northern Europe. For Ecol Manage 260:939-947

Fick SE, Hijmans RJ (2017) WorldClim 2: new 1-km spatial resolution climate surfaces for global land areas. Int J Climatol 37:4302-4315

Ficko A, Lidestav G, Ní Dhubháin Á et al (2019) European private forest owner typologies: a review of methods and use. Forest Policy Econ 99:21-31

Friedrich S, Paul C, Brandl S et al (2019) Economic impact of growth effects in mixed stands of Norway spruce and European beech - a simulation based study. For Policy Econ 104:65-80

Gamfeldt L, Snäll T, Bagchi R et al (2013) Higher levels of multiple ecosystem services are found in forests with more tree species. Nat Comms 4:1340

García-Robredo F (2018) Effect of species complementarity on financial return in mixed stands of European beech and scots pine in northern Spain. Forests 9:559

Geßler A, Keitel C, Kreuzwieser J et al (2006) Potential risks for European beech (Fagus sylvatica L.) in a changing climate. Trees 21:1-11

Giorgetta MA, Jungclaus J, Reick CH et al (2013) Climate and carbon cycle changes from 1850 to 2100 in MPI-ESM simulations for the Coupled Model Intercomparison Project phase 5. J Adv Model Earth Syst 5:572-597

Gorissen BL, Yanıkoğlu İ, den Hertog D (2015) A practical guide to robust optimization. Omega 53:124-137

Gosling E, Reith E, Knoke T et al (2020) A goal programming approach to evaluate agroforestry systems in Eastern Panama. J Environ Manag 261:110248

Griess VC, Acevedo R, Härtl F et al (2012) Does mixing tree species enhance stand resistance against natural hazards? A case study for spruce. For Ecol Manage 267:284-296

Gutsch M, Lasch-Born P, Suckow F et al (2016) Evaluating the productivity of four main tree species in Germany under climate change with static reduced models. Ann for Sci 73:401-410

Hallegatte S, Hourcade J-C, Ambrosi P (2007) Using climate analogues for assessing climate change economic impacts in urban areas. Clim Change 82:47-60

Hanewinkel M, Albrecht A, Schmidt M (2015) Können Windwurfschäden vermindert werden? Eine Analyse von Einflussgrössen. Schweizerische Zeitschrift Fur Forstwesen 166:118-128

Hanewinkel M, Cullmann DA, Schelhaas M-J et al (2013) Climate change may cause severe loss in the economic value of European forest land. Nat Clim Change 3:203-207 
Hanewinkel M, Hummel S, Cullmann DA (2010) Modelling and economic evaluation of forest biome shifts under climate change in Southwest Germany. For Ecol Manage 259:710-719

Hanewinkel M, Pretzsch H (2000) Modelling the conversion from even-aged to uneven-aged stands of Norway spruce (Picea abies L. Karst.) with a distance-dependent growth simulator. For Ecol Manage 134:55-70

Härtl FH, Höllerl S, Knoke T (2017) A new way of carbon accounting emphasises the crucial role of sustainable timber use for successful carbon mitigation strategies. Mitig Adapt Strateg Glob Change 22:1163-1192

Hernandez M, Gómez T, Molina J et al (2014) Efficiency in forest management: a multiobjective harvest scheduling model. $\mathrm{J}$ for Econ 20:236-251

Hilmers T, Biber P, Knoke T et al (2020) Assessing transformation scenarios from pure Norway spruce to mixed uneven-aged forests in mountain areas. Eur J For Res 87:267

Huntley B, Berry PM, Cramer W et al (1995) Modelling present and potential future ranges of some European higher plants using climate response surfaces. J Biogeogr 22:967

Hurmekoski E, Hetemäki L (2013) Studying the future of the forest sector: review and implications for long-term outlook studies. For Policy Econ 34:17-29

Jacobsen JB, Vedel SE, Thorsen BJ (2013) Assessing costs of multifunctional NATURA 2000 management restrictions in continuous cover beech forest management. For Int J For Res 86:575-582

Jactel H, Bauhus J, Boberg J et al (2017) Tree diversity drives forest stand resistance to natural disturbances. Curr For Rep 3:223-243

Jandl R, Spathelf P, Bolte A et al (2019) Forest adaptation to climate change-is non-management an option? Ann For Sci 76

Jorion P (1997) Value at risk. The new benchmark for controlling market risk, 1st edn. McGraw-Hill, New York

Jorion P (2009) Value at risk. The new benchmark for managing financial risk, 3rd edn. McGraw-Hill, New York, NY

Keenan RJ (2015) Climate change impacts and adaptation in forest management: a review. Ann Sci 72:145-167

Klemperer WD (1996) Forest resource economics and finance. McGraw-Hill, New York

Knoke T, Paul C, Hildebrandt P et al (2016) Compositional diversity of rehabilitated tropical lands supports multiple ecosystem services and buffers uncertainties. Nat Commun 7:11877

Knoke T, Paul C, Rammig A et al (2020) Accounting for multiple ecosystem services in a simulation of land-use decisions: Does it reduce tropical deforestation? Glob Change Biol

Köhl M, Ehrhart H-P, Knauf M et al (2020) A viable indicator approach for assessing sustainable forest management in terms of carbon emissions and removals. Ecol Indic 111:106057

Kovats SR, Valentini R, Bouwer LM et al (2014) Europe. In: Barros VR, Field CB, Dokken DJ et al (eds) Climate Change 2014: Impacts, Adaptation, and Vulnerability. Part B: Regional Aspects. Contribution of Working Group II to the Fifth Assessment Report of the Intergovernmental Panel on Climate Change, Cambridge, UK, New York, NY, USA, pp 1267-1326

Lemes P, Melo AS, Loyola RD (2014) Climate change threatens protected areas of the Atlantic Forest. Biodivers Conserv 23:357-368

Liang J, Crowther TW, Picard N et al (2016) Positive biodiversityproductivity relationship predominant in global forests. Science (New York, N.Y.) 354

Lindner M, Maroschek M, Netherer S et al (2010) Climate change impacts, adaptive capacity, and vulnerability of European forest ecosystems. For Ecol Manage 259:698-709

Magnusson L (2019) The 2019 western European heatwaves. In: European Centre for Medium-Range Weather Forecasts (ECMWF) (ed) Newsletter. Autumn 2019, Reading, UK, pp 2-3
Markowitz HM (1952) Portfolio selection. J Finance 7:77

McDaniels T, Mills T, Gregory R et al (2012) Using expert judgments to explore robust alternatives for forest management under climate change. Risk Anal Off Publ Soc Risk Anal 32:2098-2112

Mendoza GA, Prabhu R (2000) Development of a methodology for selecting criteria and indicators of sustainable forest management: a case study on participatory assessment. Environ Manage 26:659-673

Messerer K, Pretzsch H, Knoke T (2017) A non-stochastic portfolio model for optimizing the transformation of an even-aged forest stand to continuous cover forestry when information about return fluctuation is incomplete. Ann for Sci 74:2

Mina M, Bugmann H, Cordonnier T et al (2017) Future ecosystem services from European mountain forests under climate change. J Appl Ecol 54:389-401

Möhring B, Rüping U (2008) A concept for the calculation of financial losses when changing the forest management strategy. Forest Policy Econ 10:98-107

Mori AS, Lertzman KP, Gustafsson L (2017) Biodiversity and ecosystem services in forest ecosystems: a research agenda for applied forest ecology. J Appl Ecol 54:12-27

Nagendra H (2002) Opposite trends in response for the Shannon and Simpson indices of landscape diversity. Appl Geogr 22:175-186

Neumann M, Mues V, Moreno A et al (2017) Climate variability drives recent tree mortality in Europe. Glob Change Biol 23:4788-4797

Neumayer E (2013) Weak versus strong sustainability. Exploring the limits of two opposing paradigms. Edward Elgar, Cheltenham

Neuner S, Albrecht A, Cullmann D et al (2015) Survival of Norway spruce remains higher in mixed stands under a dryer and warmer climate. Glob Change Biol 21:935-946

Neuner S, Beinhofer B, Knoke T (2013) The optimal tree species composition for a private forest enterprise - applying the theory of portfolio selection. Scand J for Res 28:38-48

Nordström E-M, Holmström H, Öhman K (2013) Evaluating continuous cover forestry based on the forest owner's objectives by combining scenario analysis and multiple criteria decision analysis. Silva Fenn. 47

Ochoa S, Härtl FH, Paul C et al (2019) Cropping systems are homogenized by off-farm income - Empirical evidence from smallscale farming systems in dry forests of southern Ecuador. Land Use Policy 82:204-219

Office National de Forêts (2019) Les dégâts de la sécheresse en cartes. https://www.onf.fr/onf/+/58e::les-degats-de-la-seche resse-en-cartes.html. Accessed 10 Jan 2020

Ontl TA, Janowiak MK, Swanston CW et al (2020) Forest management for carbon sequestration and climate adaptation. J Forest 118:86-101

Pachauri, RK, Mayer, L, IPCC SYR TSU (eds) (2015) Climate change 2014. Synthesis report. Intergovernmental Panel on Climate Change, Geneva, Switzerland

Palma CD, Nelson JD (2009) A robust optimization approach protected harvest scheduling decisions against uncertainty. Can $\mathbf{J}$ for Res 39:342-355

Pasalodos-Tato M, Mäkinen A, Garcia-Gonzalo J et al (2013) Review. Assessing uncertainty and risk in forest planning and decision support systems. Review of classical methods and introduction of new approaches. For Syst 22:282

Paul C, Brandl S, Friedrich S et al (2019) Climate change and mixed forests: how do altered survival probabilities impact economically desirable species proportions of Norway spruce and European beech? Ann Sci 76:1-14

Popkin G (2019) The forest question. Nature

Pretzsch H (1997) Analysis and modeling of spatial stand structures. Methodological considerations based on mixed beech-larch stands in Lower Saxony. For Ecol Manag, 237-253 
Pretzsch H (2002) Application and evaluation of the growth simulator SILVA 2.2 for forest stands, forest estates and large regions. Forstwissenschaftliches Centralblatt 121:28-51

Pretzsch H (2005) Diversity and productivity in forests. evidence from long-term experimental plots. In: Scherer-Lorenzen M, Körner C, Schulze E-D (eds) Forest diversity and function: temperate and boreal systems. Springer, Heidelberg, pp 41-64

Pretzsch H, Biber P, Dursky J (2002) The single tree-based stand simulator SILVA. Construction, application and evaluation. For Ecol Manage 162:3-21

Pretzsch H, Forrester DI, Bauhus J (eds) (2017) Mixed-species forests. Springer, Berlin

Radke N, Keller K, Yousefpour R et al (2020) Identifying decisionrelevant uncertainties for dynamic adaptive forest management under climate change. Clim Change 163:891-911

Radke N, Yousefpour R, von Detten R et al (2017) Adopting robust decision-making to forest management under climate change. Ann Sci 74:181

Rennenberg H, Seiler W, Matyssek R et al (2004) European beech (Fagus sylvatica L.) - A forest tree without future in the south of Central Europe? Allgemeine Forst Und Jagdzeitung 175:210-224

Rock J, Badeck F-W, Harmon ME (2008) Estimating decomposition rate constants for European tree species from literature sources. Eur J Forest Res 127:301-313

Roessiger J, Griess VC, Härtl F et al (2013) How economic performance of a stand increases due to decreased failure risk associated with the admixing of species. Ecol Model 255:58-69

Schuldt B, Buras A, Arend M et al (2020) A first assessment of the impact of the extreme 2018 summer drought on Central European forests. Basic Appl Ecol 45:86-103

Schütz J-P, Götz M, Schmid W et al (2006) Vulnerability of spruce (Picea abies) and beech (Fagus sylvatica) forest stands to storms and consequences for silviculture. Eur J For Res 125:291-302

Seidl R, Albrich K, Erb K et al (2019) What drives the future supply of regulating ecosystem services in a mountain forest landscape? For Ecol Manage 445:37-47

Shavazipour B, Stewart TJ (2019) Multi-objective optimisation under deep uncertainty. Oper Res Int J 55:43

Sykes MT, Prentice IC (1996) Climate change, tree species distributions and forest dynamics: a case study in the mixed conifer/ northern hardwoods zone of northern Europe. Clim Change 34:161-177
Thiele JC, Nuske RS, Ahrends B et al (2017) Climate change impact assessment-A simulation experiment with Norway spruce for a forest district in Central Europe. Ecol Model 346:30-47

Thuiller W, Lavorel S, Araújo MB et al (2005) Climate change threats to plant diversity in Europe. Proc Natl Acad Sci USA 102:8245-8250

Thünen Institut. (2014) Dritte Bundeswaldinventur - Ergebnisdatenbank Thünen Institut. (2019) Kohlenstoffinventur 2017 - Ergebnisdatenbank

Tom SM, Fox CR, Trepel C et al (2007) The neural basis of loss aversion in decision-making under risk. Science 315:515-518

Uhde B, Heinrichs S, Stiehl CR et al (2017) Bringing ecosystem services into forest planning - Can we optimize the composition of Chilean forests based on expert knowledge? Forest Ecology and Management 404:126-140. http://www.sciencedirect.com/scien ce/article/pii/S0378112717304437

Vincent JR, Binkley CS (1993) Efficient multiple-use forestry may require land-use specialization. Land Econ 69:370

Walker WE, Lempert RJ, Kwakkel JH (2013) Deep uncertainty. In: Gass SI, Fu MC (eds) Encyclopedia of operations research and management science, 3rd edn. Springer, US, Boston, MA, pp 395-402

WorldClim. (2018) WorldClim - Global Climate Data. Free data for ecological modelling and GIS - Bioclimatic variables in $30 \mathrm{sec}-$ onds resolution.

Yousefpour R, Jacobsen JB, Thorsen BJ et al (2012) A review of decision-making approaches to handle uncertainty and risk in adaptive forest management under climate change. Ann Sci 69:1-15. https://doi.org/10.1007/s13595-011-0153-4

Zimmermann L, Raspe S (2020) Im Norden dritter Dürresommer in Serie. Niederschlag - Temperatur - Bodenfeuchte. LWF aktuell:52-54. https://www.lwf.bayern.de/mam/cms04/bodenklima/dateien/a127_wks.pdf

Zimmermann L, Raspe S (2021) Herbst 2020: zu warm, zu trocken und zu »sonnig «. Niederschlag - Temperatur - Bodenfeuchte. LWF aktuell:56-58

Publisher's Note Springer Nature remains neutral with regard to jurisdictional claims in published maps and institutional affiliations. 